\title{
Global turnover of histone post-translational modifications and variants in human cells
}

Barry M Zee ${ }^{1 \dagger}$, Rebecca S Levin ${ }^{2 \dagger}$, Peter A DiMaggio ${ }^{1}$, Benjamin A Garcia ${ }^{1,2^{*}}$

\begin{abstract}
Background: Post-translational modifications (PTMs) on the N-terminal tails of histones and histone variants regulate distinct transcriptional states and nuclear events. Whereas the functional effects of specific PTMs are the current subject of intense investigation, most studies characterize histone PTMs/variants in a non-temporal fashion and very few studies have reported kinetic information about these histone forms. Previous studies have used radiolabeling, fluorescence microscopy and chromatin immunoprecipitation to determine rates of histone turnover, and have found interesting correlations between increased turnover and increased gene expression. Therefore, histone turnover is an understudied yet potentially important parameter that may contribute to epigenetic regulation. Understanding turnover in the context of histone modifications and sequence variants could provide valuable additional insight into the function of histone replacement.
\end{abstract}

Results: In this study, we measured the metabolic rate of labeled isotope incorporation into the histone proteins of HeLa cells by combining stable isotope labeling of amino acids in cell culture (SILAC) pulse experiments with quantitative mass spectrometry-based proteomics. In general, we found that most core histones have similar turnover rates, with the exception of the H2A variants, which exhibit a wider range of rates, potentially consistent with their epigenetic function. In addition, acetylated histones have a significantly faster turnover compared with general histone protein and methylated histones, although these rates vary considerably, depending on the site and overall degree of methylation. Histones containing transcriptionally active marks have been consistently found to have faster turnover rates than histones containing silent marks. Interestingly, the presence of both active and silent marks on the same peptide resulted in a slower turnover rate than either mark alone on that same peptide. Lastly, we observed little difference in the turnover between nearly all modified forms of the H3.1, H3.2 and H3.3 variants, with the notable exception that $\mathrm{H} 3.2 \mathrm{~K} 36 \mathrm{me} 2$ has a faster turnover than this mark on the other $\mathrm{H} 3$ variants.

Conclusions: Quantitative proteomics provides complementary insight to previous work aimed at quantitatively measuring histone turnover, and our results suggest that turnover rates are dependent upon site-specific posttranslational modifications and sequence variants.

\section{Background}

In eukaryotes, stable genetic storage is accomplished through the local organization of DNA around histone proteins to form the chromatin fiber. Histones have been long recognized as the structural scaffolds of chromatin, but more recent research has suggested that they possess a broader role. The epigenetic influence of histones is mediated primarily by post-translational

\footnotetext{
* Correspondence: bagarcia@princeton.edu

+ Contributed equally

'Department of Molecular Biology, Princeton University, Princeton NJ, 08544, USA

Full list of author information is available at the end of the article
}

modifications (PTMs) and also by selective deposition of histone variants, which in combination influence gene transcription and other processes such as DNA damage and replication [1]. In particular, histone PTMs such as trimethylation of lysine 4 on histone H3 (H3K4me3) recruit or displace other proteins that regulate transcription, such as the chromatin remodeler nucleosome remodeling factor (NURF) [2]. Although the underlying mechanism through which histone variants influence gene expression is unclear, certain histone variants have been shown to be linked with specialized genomic roles. For instance, replication-independent H3.3 variant deposition occurs at the transcriptional start sites in 
various organisms [3]. This specificity probably involves recognition by variant-specific remodeling complexes and chaperones, as is the case for Mis16 and Mis18 interaction with the centromere-specific $\mathrm{H} 3$ variant centromere protein (CENP)-A [4].

Implicit to the current theories of histone epigenetic regulation is that nucleosome occupancy over specific genomic regions is intimately linked to transcription [5]. The biological consequences of histone turnover were first explored with ${ }^{14} \mathrm{C}$-and ${ }^{3} \mathrm{H}$-radiolabeling, and among the findings was that specific histone pools were observed to turnover both dependently and independently of DNA replication [6,7]. It is now known that the majority of histone synthesis is synchronized with Sphase, and that $\mathrm{H} 3.1$ and $\mathrm{H} 3.3$ are deposited in a replication-dependent and-independent manner, respectively $[8,9]$. Expression of the histone genes, which are often clustered within chromosomes, is further regulated at the level of messenger (m)RNA expression, pre-mRNA processing and mRNA stability [10]. Offsetting histone synthesis and deposition is histone degradation and eviction; for instance Saccharomyces cerevisiae SWR1 and human SRCAP (sucrose non-fermentation (SNF)2 $\mathrm{C}$-AMP response element binding protein binding protein (CBP) activator protein replaces $\mathrm{H} 2 \mathrm{~A}$ with $\mathrm{H} 2 \mathrm{~A} . \mathrm{Z}$ in an ATP-dependent manner [11]. Excess production of histones is known to result in defects in mitotic chromosome segregation $[12,13]$. Thus, both histone synthesis/deposition and histone degradation/eviction must occur at approximately equal rates to maintain steady state DNA-bound histone levels and nucleosomal and genomic stability. Yet the absolute value of the rates for each process (synthesis/deposition and degradation/eviction) can differ significantly depending upon the enzyme and substrate. We describe the absolute values of these rates as turnover. In contrast to the relatively slow turnover of histones, which are known to have half-lives in the order of days as determined by radiolabeling studies, the rapid modification of histones after synthesis and incorporation into chromatin is known to be a rapid process [14].

More recent studies exploring histone turnover have mostly relied on tagging histones with green fluorescent protein, Myc or other epitopes to allow fluorescence recovery after photobleaching, chromatin immunoprecipitation or other techniques to measure turnover. One notable finding includes the existence of at least two pools of $\mathrm{H} 1$ with distinct DNA exchange rates in 3T3 cells [15]. Other studies involving the mapping of histone turnover to the genome have shown increased histone turnover on promoters relative to coding regions in S. cerevisiae [16], and on binding sites for trithorax group proteins relative to binding sites for polycomb group proteins in Drosophila melanogaster S2 cells
$[17,18]$. These studies suggest that increased turnover within a particular genomic region disrupts the local chromatin environment and renders genes accessible to transcription factors, subsequently leading to gene activation. The results from $D$. melanogaster also point to an intriguing correlation between increased histone turnover and binding of the origin recognition complex, raising questions about the connection between DNA replication and chromatin [18].

A valuable complement to these ongoing investigations is the study of histone turnover when distinct sitespecific PTMs and the specific histone variants are simultaneously considered. To obtain a quantitative measure of global histone turnover as a function of modification status and type of sequence variant, we designed a time course experiment using stable isotope labeling with amino acids in cell culture (SILAC) in conjunction with high-resolution mass spectrometry (MS). MS enables precise quantification of both histone posttranslational modification sites, and allows sequence variants to be identified, thus we believe these attributes qualify MS as a useful technique for studying histone biology in general [19]. Furthermore, because we studied endogenous histones, there are no tags to interfere with higher-order chromatin structure and our measurements accurately capture global in vivo global histone turnover. In this study, we report that turnover rates of histone proteins vary widely depending upon the modification status and sequence variant. Our approach also produced important quantitative information, thus providing a useful and complementary platform for understanding chromatin biology.

\section{Results and discussion}

To track the turnover of histone variants and PTMs in unsynchronized growing cells, we cultured HeLa cells in standard Joklik media and then transferred the cells to media containing exclusively ${ }^{13} \mathrm{C}_{6}{ }^{15} \mathrm{~N}_{2}$-lysine, which is essentially similar to performing pulse SILAC experiments (Figure 1). Histones found to contain the isotopically 'heavy' ${ }^{13} \mathrm{C}_{6}{ }^{15} \mathrm{~N}_{2}$-lysine residues were termed 'new', as they are synthesized after the introduction of the heavy media. This metabolic incorporation can be assessed by direct examination of the population of peptides on days 0,1 and 6 (post incubation in heavy media) (Figure 1) At day 0 we observed a doubly charged peptide at 724.375 mass to charge ratio $(\mathrm{m} / \mathrm{z})$, which after tandem MS (MS/MS) experiments (data not shown) was found to correspond to the histone H3 7383 residue peptide, ${ }_{\mathrm{pr}}$ EIAQDFK $_{\mathrm{pr}}$ TDLR $(\mathrm{pr}=$ propionyl amide group from chemical derivatization). At day 1 we observed a decrease in this peptide, and the appearance of another peptide at $728.382 \mathrm{~m} / \mathrm{z}$. These peptides chromatographically co-elute and possess the same charge 


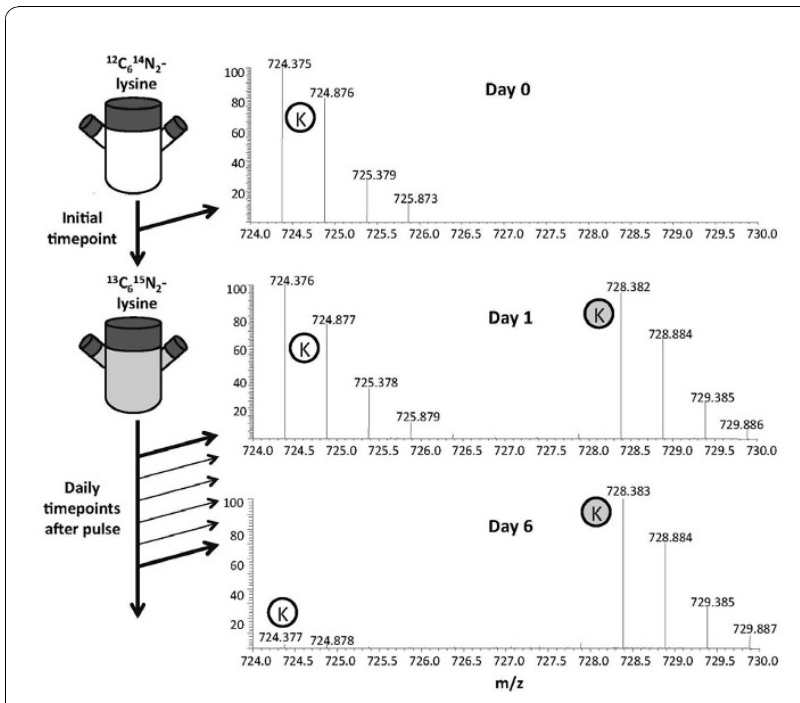

Figure 1 Experimental design. HeLa S3 cells were cultured in unlabeled ${ }^{12} \mathrm{C}_{6}{ }^{14} \mathrm{~N}_{2}$-lysine media, and transitioned into labeled ${ }^{13} \mathrm{C}_{6}{ }^{15} \mathrm{~N}_{2}$-lysine media. Daily samples were collected and analyzed by mass spectrometry (MS). MS spectra detected the ${ }^{13} \mathrm{C}_{6}{ }^{15} \mathrm{~N}_{2}$-lysine labeled peptide (gray circle, $\mathrm{H} 3$ 73-83) co-eluting with the respective unlabeled peptide (white circle) after the pulse at days 0, 1 and 6 .

state, which is a characteristic of ${ }^{13} \mathrm{C}^{15} \mathrm{~N}$ labeled isotopic peptides, but the heavier peptide contains an overall mass shift that is an integer divisible of $8.011 \mathrm{Da}(\Delta \mathrm{m} / \mathrm{z}$ $=\sim 4 \mathrm{Da}$ on a $2+$ charge peptide). By day 6 , the heavier peptide at $728.382 \mathrm{~m} / \mathrm{z}$ was the most abundant species, and the lighter peptide at $724.375 \mathrm{~m} / \mathrm{z}$ is almost completely gone (Figure 1). MS/MS interrogation of the peptide at $728.382 \mathrm{~m} / \mathrm{z}$ (Figure 2) identified it as having

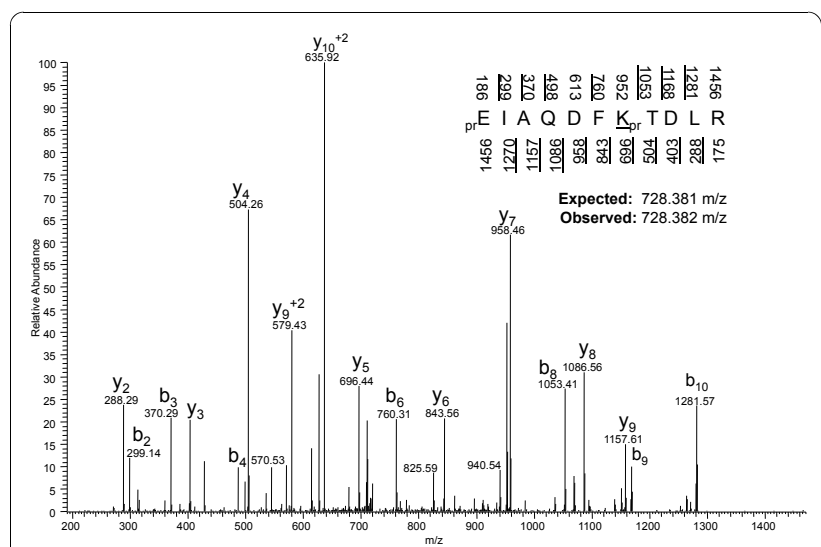

Figure 2 Tandem mass spectrometry (MS/MS) spectrum of labeled lysine peptide. MS/MS of the $\mathrm{H} 3$ 73-83 peptide unmodified on $\mathrm{K} 79$ and labeled with ${ }^{13} \mathrm{C}_{6}{ }^{15} \mathrm{~N}_{2}$-lysine isotope. Underlined nominal masses above and below the sequence denote the $b$ and $y$ ions respectively that were annotated from the spectrum. The expected and observed mass to charge ratio $(\mathrm{m} / \mathrm{z})$ for the $\left[\mathrm{M}+2 \mathrm{H}^{+}\right]^{2+}$ precursor ion is provided. $\mathrm{pr}=$ Propionyl (heavy, D5-labeled) the same sequence as the respective unlabeled peptide, but with all of the lysines substituted by the ${ }^{13} \mathrm{C}_{6}{ }^{15} \mathrm{~N}_{2}$ lysine. For all histone peptides that we studied in our MS experiments, we observed at least one corresponding isotopically labeled peptide during the time course (see Additional file 1, Additional file 2).

Additionally, on histone peptides containing two or more lysine residues, we detected peptide forms that were fully unlabeled (all ${ }^{12} \mathrm{C}_{6}{ }^{14} \mathrm{~N}_{2}$-lysines), fully labeled (all ${ }^{13} \mathrm{C}_{6}{ }^{15} \mathrm{~N}_{2}$-lysines) and partially labeled (a combination of ${ }^{12} \mathrm{C}_{6}{ }^{14} \mathrm{~N}_{2}$ - and ${ }^{13} \mathrm{C}_{6}{ }^{15} \mathrm{~N}_{2}$-lysines) (see Additional file 3). In general, for all the peptides observed in all of the histone proteins, the partially labeled and fully labeled peptides accumulated in relative abundance over the time course and reached a final steady state level approximately 4 days after introduction into ${ }^{13} \mathrm{C}_{6}{ }^{15} \mathrm{~N}_{2}$ lysine heavy media (Figure 3), indicating that the intracellular lysine pool became increasingly populated with ${ }^{13} \mathrm{C}_{6}{ }^{15} \mathrm{~N}_{2}$-lysine. A minute fraction of ${ }^{12} \mathrm{C}_{6}{ }^{14} \mathrm{~N}_{2}$-lysine remained within the cells, presumably due to macromolecular decomposition during the timescale of our experiments, and was observed in both the partially labeled and fully unlabeled peptides.

To model the rate of accumulation of the newly labeled histone peptides and the corresponding depletion rate of the old unlabeled peptides, we fitted the relative distributions of the different labeled states for each peptides to a set of differential equations similar to those previously published (Figure 4, see Additional file 4)[20]. Our model accounts for all states corresponding to the

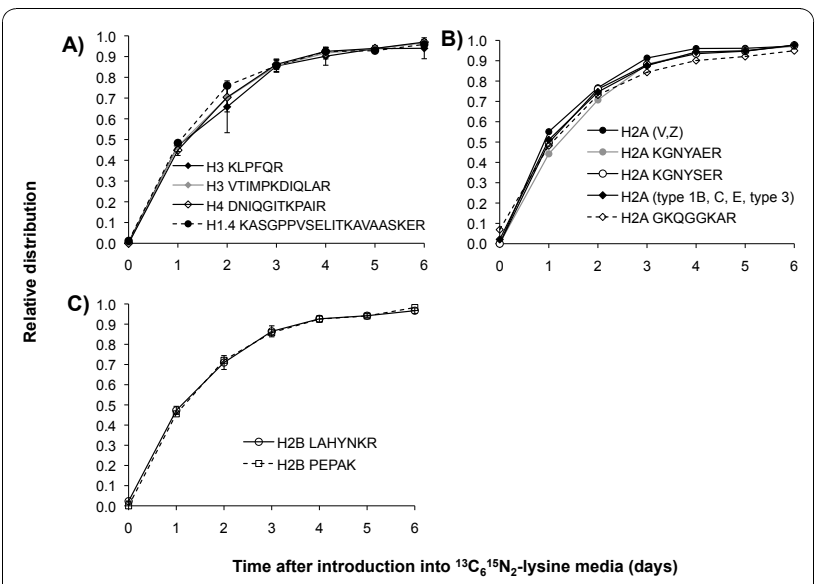

Figure 3 Isotopic labeling of histone variants. Average relative distribution (markers) of the fully isotopically labeled (A) $\mathrm{H} 3, \mathrm{H} 4$ and H1.4 peptides, (B) H2A peptides and (C) H2B variant peptides across the labeling time course. Note the gradual accumulation of the fully labeled peptide as time increases. The peptide labeled as H2A $(V, Z)$ corresponds to the sequence ATIAGGGVIPHIHK, and the peptide labeled as H2A (types $1 B, C, E$ and 3 ) corresponds to the sequence NDEELNKLLGR. All other peptides correspond to $>3$ different histone proteins. Vertical lines represent standard deviation. 


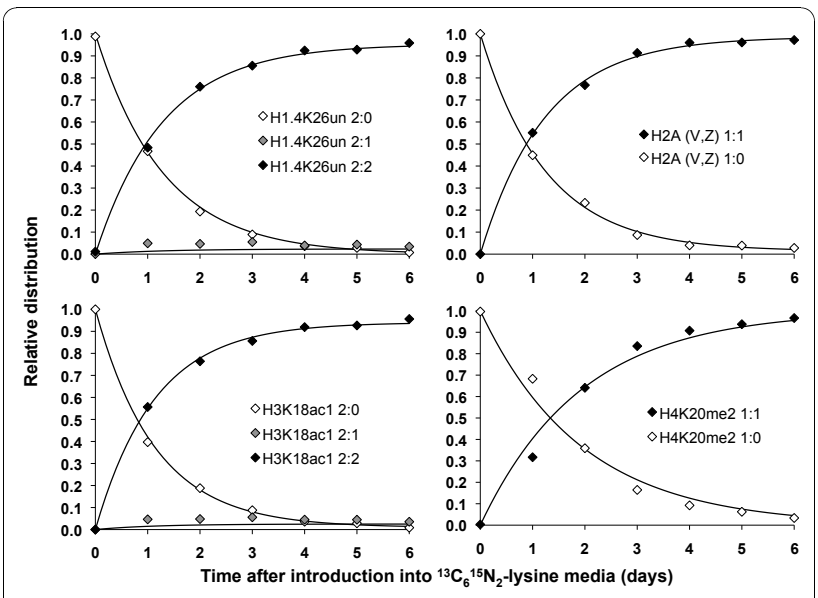

Figure 4 Modeling of histone turnover. Average relative distribution (markers) of various isotopically labeled and modified histone peptides on histones $\mathrm{H} 1.4, \mathrm{H} 2 \mathrm{~A}, \mathrm{H} 3$ and $\mathrm{H} 4$ across the labeling time course (days). Lines represent optimized fits of the observed relative distributions for the particular peptide.

fully labeled, fully unlabeled and partially labeled peptides. An assumption implicit to our method of normalization and modeling is that the post-translationally modified forms, when summed across all isotopically labeled states, remain at steady state relative to each other. We confirmed that the standard deviations of the relative abundances for each modified peptide, summed over all the labeled states and across the time course, were $<0.051$ (see Additional file 5). This is the threshold at which $95 \%$ of the observed variability cannot be accounted for by $10 \%$ of the instrument measurement variability, a common metric for accessing the reproducibility of MS experiments [21]. Based upon these measurements, we concluded that all of the peptides occurred at steady state throughout the experiment.

Next, we extrapolated the turnover rate for bulk histones (Figure 3, Table 1). For this purpose, we examined the 24-35 (DNIQGITKPAIR) H4 peptide, the 33-53 (KASGPPVSELITKAVAASKER) H1.4 peptide and the 65-70 (KLPFQR) and 117-128 (VTIMPKDIQLAR) H3 peptides (labeled amino acids underlined), which our laboratory has previously found are not modified for HeLa S3 (unpublished data). Thus, we postulated that the measured turnover rates for these peptides should reflect the general turnover rates of bulk $\mathrm{H} 4, \mathrm{H} 3$ and H1.4 histones, respectively. We found that H1.4 has a faster turnover than $\mathrm{H} 3$, which in turn has a slightly faster turnover than $\mathrm{H} 4$. These findings are consistent with our previous work, in which we labeled HeLa S3 cells with ${ }^{13} \mathrm{CD}_{3}$-methionine and tracked incorporation of the heavy methionine isotope, with a $4.021 \mathrm{~m} / \mathrm{z}$ shift for every new methionine added [22]. Histone H1.4 is
Table 1 Histone post-translational modification and variant-specific turnover.1

\begin{tabular}{|c|c|c|c|}
\hline Peptide $^{2-4,6}$ & $\begin{array}{l}\text { Turnover, per } \\
\text { day }^{5}\end{array}$ & Peptide $^{2-4,6}$ & $\begin{array}{l}\text { Turnover, per } \\
\text { day }^{5}\end{array}$ \\
\hline H3K65un & $0.6230 \pm 0.0001$ & H3K27unK36un & $1.9213 \pm 0.0001$ \\
\hline H3K122un & $0.6400 \pm 0.0001$ & H3K27me1 & $1.1391 \pm 0.0000$ \\
\hline H3K4un & 0.6638 & H3K36me1 & 1.691 \\
\hline H3K4me1 & $0.4863 \pm 0.0000$ & H3K27me2 & $0.8207 \pm 0.0000$ \\
\hline H3K56un & $0.6378 \pm 0.0000$ & H3K36me2 & $1.0892 \pm 0.0000$ \\
\hline $\mathrm{H} 3 \mathrm{~K} 56 \mathrm{ac1}$ & $2.4335 \pm 0.0014$ & H3K27me3 & $0.5148 \pm 0.0000$ \\
\hline H3K18K23un & $0.6806 \pm 0.0001$ & H3K27me1K36me2 & $0.7540 \pm 0.0000$ \\
\hline $\mathrm{H} 3 \mathrm{~K} 18 / \mathrm{K} 23 \mathrm{ac} 1^{4}$ & $0.8793 \pm 0.0000$ & H3K27me2K36me1 & $0.6210 \pm 0.0001$ \\
\hline $3 \mathrm{ac1}$ & 1.1446 & $\mathrm{H} 3 \mathrm{~K} 2 \mathrm{~T}$ & 0.45 \\
\hline H3K79un & $0.6785 \pm 0.0001$ & H3K27me3K36me1 & $0.3681 \pm 0.0000$ \\
\hline H3K79me1 & $0.4526 \pm 0.0000$ & H3K27me1K36me3 & $0.4547 \pm 0.0000$ \\
\hline H3K79me2 & $0.3841 \pm 0.0000$ & H4K5K8K12K16un & $0.6495 \pm 0.0000$ \\
\hline H3K9unK14un & $1.1335 \pm 0.0001$ & $\begin{array}{l}\mathrm{H} 4 \mathrm{~K} 5 / \mathrm{K} 8 / \mathrm{K} 12 / \\
\mathrm{K} 16 \mathrm{ac}^{4}\end{array}$ & $0.7773 \pm 0.0000$ \\
\hline 21 & $0.7967 \pm 0.0001$ & $\begin{array}{l}\mathrm{H} 4 \mathrm{~K} 5 / \mathrm{K} 8 / \mathrm{K} 12 / \\
\mathrm{K} 6 \mathrm{ac} 2^{4}\end{array}$ & $0.9819 \pm 0.0000$ \\
\hline $\mathrm{H} 3 \mathrm{KC}$ & $0.6620 \pm 0.0000$ & $\begin{array}{l}\mathrm{H} 4 \mathrm{~K} 5 / \mathrm{K} 8 / \mathrm{K} 12 / \\
{\mathrm{K} 16 \mathrm{ac} 3^{4}}\end{array}$ & $1.0423 \pm 0.0000$ \\
\hline H3K9me3 & $0.4652 \pm 0.0000$ & H4K5K8K12K16ac4 & $1.0056 \pm 0.0000$ \\
\hline $\mathrm{H} 3 \mathrm{~K} 9 / \mathrm{K}_{14 \mathrm{ac}}{ }^{4}$ & $1.3393 \pm 0.0001$ & H4K20un & $2.2672 \pm 0.0005$ \\
\hline H3K9me1K14ac1 & $0.9205 \pm 0.0000$ & H4K20me1 & $1.3340 \pm 0.0002$ \\
\hline H3K9me2K14ac1 & $0.6454 \pm 0.0000$ & H4K20me2 & $0.5177 \pm 0.0000$ \\
\hline $\mathrm{H} 1.4 \mathrm{~K} 26 \mathrm{un}$ & $0.7721 \pm 0.0000$ & H4K20me3 & $0.3307 \pm 0.0000$ \\
\hline H4K31un & $0.6182 \pm 0.0001$ & $\begin{array}{l}\text { H2A: } \\
\text { ATIAGGGVIPHIHK }\end{array}$ & $0.8016 \pm 0.0001$ \\
\hline $\begin{array}{l}\text { H2A: } \\
\text { GKQGGKAR }\end{array}$ & $0.7222 \pm 0.0000$ & $\begin{array}{l}\text { H2A: } \\
\text { NDEELNKLLGR }\end{array}$ & $0.7135 \pm 0.0000$ \\
\hline H2A: KGNYAER & $0.6311 \pm 0.0000$ & H2B: LAHYNKR & $0.6448 \pm 0.0000$ \\
\hline H2A: KGNYSER & $0.7215 \pm 0.0001$ & H2B: PEPAK & $0.6293 \pm 0.0000$ \\
\hline
\end{tabular}

${ }^{1}$ Absolute turnover values (mean \pm standard deviation per day) extrapolated from the relative distribution of the isotopically labeled bulk $\mathrm{H} 3, \mathrm{H} 4$ and $\mathrm{H} 1.4$ peptides with a particular post-translational modification.

${ }^{2} \mathrm{me}=$ methyl

${ }^{3} \mathrm{ac}=$ acetyl

${ }^{4} \mathrm{The} \mathrm{H} 2 \mathrm{~A}$ and $\mathrm{H} 2 \mathrm{~B}$ turnover values are averages of all histone variants containing the specific peptide sequence.

${ }^{5}$ The model was iterated 200 times for each individual peptide, where the average and standard deviation were taken for parameters within $105 \%$ of the determined optimum parameter.

${ }^{6}$ For H3K18/K23ac1, H3K9/K14ac1, and H4K5/K8/K12/K16ac1, ac2 and ac3, the localization of the acetyl(s) on the multiple lysines was not determined.

known to repress transcription and condense chromatin more efficiently than other $\mathrm{H} 1$ subtypes, partly due to its increased chromatin binding affinity $[23,24]$. It is likely that the faster turnover of H1.4 compared with $\mathrm{H} 3$ and $\mathrm{H} 4$ is not due to a difference in epigenetic function, but rather to its different location relative to the core nucleosome. In the future, it would be interesting to examine how H1.4 turnover compares relative to 
other less efficient chromatin-compacting $\mathrm{H} 1$ subtypes, such as H1.1 and H1.2.

We also examined peptides from several $\mathrm{H} 2 \mathrm{~A}$ and H2B variants. Similar to the aforementioned unmodified peptides for $\mathrm{H} 1.4, \mathrm{H} 3$ and $\mathrm{H} 4$, we never observed forms of the $\mathrm{H} 2 \mathrm{~A}$ or $\mathrm{H} 2 \mathrm{~B}$ peptides to be modified and thus reasoned that they also represented bulk turnover of their respective protein (Figure 3, Figure 4). However, some of the tryptic peptides are not unique to a particular variant, as many variants are largely homologous (Table 1). For example, we could only link the peptide NDEELNKLLGR, which is found in H2B types 1-C, 3 and $1-B / E$, to the average turnover associated with all the homologous histones. We observed that the $\mathrm{H} 2 \mathrm{~B}$ variants containing the peptide sequence LAHYNKR or PEPAK had turnover rates similar to $\mathrm{H} 3$ and $\mathrm{H} 4$ (see Additional file 6). By contrast, a broader range of turnover values was found for the $\mathrm{H} 2 \mathrm{~A}$ variants, with some being notably faster than H1.4. This wide range of turnover values observed for the $\mathrm{H} 2 \mathrm{~A}$ variants suggests that different variants may serve different purposes in chromatin assembly. For instance, the human $\mathrm{H} 2 \mathrm{~A}$ variants that contain the sequence ATIAGGGVIPHIHK, which include $\mathrm{H} 2 \mathrm{AZ}$, have the fastest turnover (see Additional file 6). Intriguingly, $\mathrm{H} 2 \mathrm{AZ}$ is known to localize specifically to transcriptional start sites, and the increased turnover is consistent with previous work showing that histones over promoters have a faster turnover than histones over the gene coding region $[16,25]$. It is important to note that $\mathrm{H} 2 \mathrm{AZ}$ localization over promoters does not indicate that $\mathrm{H} 2 \mathrm{AZ}$ is associated with gene activation, but is currently believed to bind to and prime silent promoters for subsequent activation [26]. Despite the differences in turnover values between the core histones, all the core peptides have a turnover rate in the order of $\ln (2)=0.6931 /$ day, which is approximately the expected rate if half of peptide population become labeled after each day. Thus, with few exceptions, bulk $\mathrm{H} 1.4, \mathrm{H} 2 \mathrm{~A}, \mathrm{H} 2 \mathrm{~B}, \mathrm{H} 3$ and $\mathrm{H} 4$ peptides generally turnover at a rate indistinguishable from the rate predicted from HeLa division approximately every 24 hours. This is consistent with previous work showing that most newly synthesized histones are deposited onto newly replicated DNA during $\mathrm{S}$ phase, and that the different histone families are synthesized in equal stoichiometry with each other [12,27].

To place our bulk histone turnover values in the context of previous work, our finding that specific $\mathrm{H} 2 \mathrm{~A}$ variants have faster turnover than the other core histones is consistent with previous radiolabeling work with tritiated amino acids in Friend murine erythroleukemia cells [28], Another radiolabeling study that administered tritiated water to mice and examined liver histones found that histone turnover generally occurs on the same time scale as cellular proliferation, which is in excess of 100 days for these cell types [29,30]. Despite the heterogeneity of cell types with vastly different proliferation rates in adult tissue, the whole-animal work is similar to our findings in HeLa cells; namely, that most bulk histones turn over with the cell cycle.

We next examined histone turnover as a function of their PTM status (Figure 5, Figure 6, Table 2). We defined the relative turnover as the turnover with respect to the unmodified peptide, in contrast to the absolute turnover we have discussed previously. Among the notable findings, we observed that the relative turnover of acetylated histones is significantly faster than that of methylated histones (Wilcoxon rank sum, $p=$ $\left.6.1 \times 10^{-5}\right)$. For instance, a peptide containing H4K20me2 has a slower turnover rate than H4K31un (general $\mathrm{H} 4$ turnover), whereas the triacetylated H4K5/ K8/K12/K16ac3 has a faster turnover than H3K31un (Figure 5,d Table 2). Furthermore, progressively acetylated and methylated peptides have a faster and slower turnover, respectively, than their unmodified peptide counterparts. For instance, the doubly acetylated H3K18acK23ac peptide has a faster turnover than the monoacetyl H3K18/K23ac1 peptide, which in turn has a faster turnover than the H3K18unK23un peptide (Table 2; see Additional file 7). Additionally, the monomethylated H3K9me1 peptide has a slower turnover than the respective unmodified peptide (Figure 6 , Table 2). Interestingly, we also observed a trend for peptides with transcriptionally active PTMs, such as H3K36me2, to have

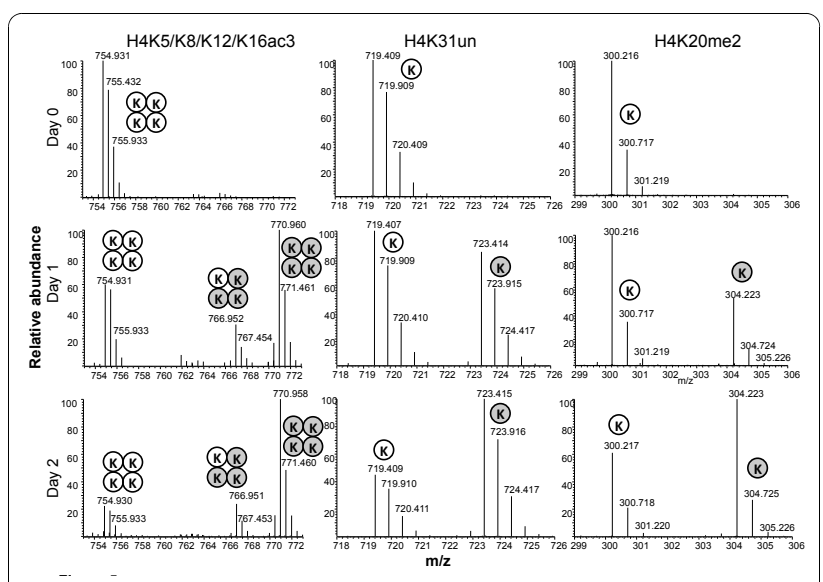

Figure $\mathbf{5}$ Turnover of modified $\mathbf{H} \mathbf{4}$ peptides. Mass spectrometry spectra of the $\mathrm{H} 4$ triacetylated 4-16 peptide (H4K5K8K12K16ac3), unmodified 24-35 peptide (H4K31 un) and dimethylated 20-23 peptide (H4K20me2) during the labeling time course. Isotopic distributions of peptides that were ${ }^{12} \mathrm{C}_{6}{ }^{14} \mathrm{~N}_{2}$-lysine unlabeled (white circle) or ${ }^{13} \mathrm{C}_{6}{ }^{15} \mathrm{~N}_{2}$-lysine labeled (gray circle) are denoted on the spectra. Note the intermediate isotopic distribution (one white circle + three gray circles) of the 4-16 peptide has three of its four lysines labeled with ${ }^{13} \mathrm{C}_{6}{ }^{15} \mathrm{~N}_{2}$-lysine. 


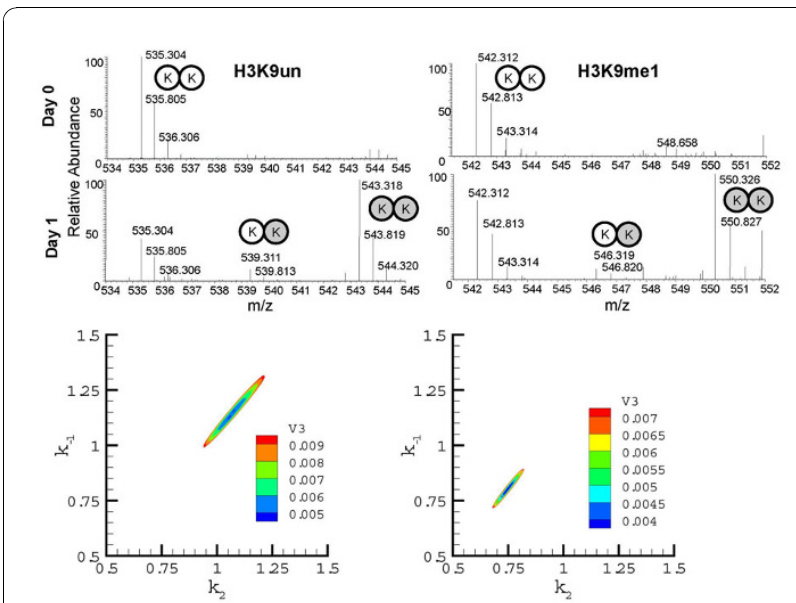

Figure 6 Effect of post-translational modifications status on $\mathrm{H3}$ turnover. Mass spectrometry (MS) spectrum of the H3 9-17 peptide (left) unmodified and (right) monomethylated on K9 collected from cells before and 1 day after the labeling time course. Contour plots below the H3K9un and H3K9me1 MS spectra are shown for the optimization of the turnover parameter $\left(k_{-1}\right)$ versus the addition of two labeled lysines $\left(k_{2}\right)$, where the contours represent values (color bar) of the objective/error function of the model in explaining the variability of the data. The boundaries of the contours equal $z(\mathrm{k}) \times$ $\left(1+3 / 11 \times F_{0.05}(3,11)\right)$, where $z(k)$ is the global minimum of the calculated objective value for the H3K9un and H3K9me1 optimization. Note the lack of overlap of the two contours.

faster relative turnovers than peptides with silent PTMs, such as H3K27me2 (Kruskal-Wallis, $p=6.3 \times 10^{-4}$ ).

How acetylation and methylation structurally affect the nucleosome itself is not entirely clear. Some notable examples of a direct structural effect of histone PTMs and nucleosomal structure are the electrostatic interaction between the $\mathrm{H} 4$ tail with respect to $\mathrm{H} 2 \mathrm{~A} / \mathrm{H} 2 \mathrm{~B}$ on the adjacent nucleosome [31], the electrostatic interaction between H3K56ac and the DNA backbone [32], and the general destabilization of the nucleosome bound to positively supercoiled DNA by the hyperacetylated histones $\mathrm{H} 3$ and $\mathrm{H} 4$ [33]. The acetyl moiety removes the positive charge from lysines due to resonance effects of the carbonyl group, whereas the methyl moiety stabilizes charge by raising the acid dissociation constant (pKa) of the remaining acidic protons. We believe that our PTM-specific data supports a general model in which changes to higher-order chromatin structure via charge stabilization or removal respectively impedes or facilitates, subsequent chromatin remodeling. ATPdependent chromatin remodeling generally proceeds via three pathways: nucleosome sliding along the DNA, nucleosome conformational change, and nucleosome eviction from the DNA $[34,35]$. Because we measured turnover by quantifying the appearance of isotopically labeled histones after a pulse, our turnover measurements may reflect the activity of remodelers and
Table 2 Relative turnover of $\mathrm{H} 3$ and $\mathrm{H} 4$ modified peptides

\begin{tabular}{lll}
\hline Peptide $^{1,2}$ & ${\text { Relative } \text { turnover }^{3}}^{\text {E }}$ & Epigenetic Function $^{\mathbf{4} 5}$ \\
\hline H3K4me1 & 0.7326 & A [52] \\
H3K9me1 & 0.7029 & A [52] \\
H3K9me2 & 0.5840 & S [52] \\
H3K9me3 & 0.4104 & S [52] \\
H3K9/K14ac1 & 1.1816 & A [38] \\
H3K18/K23ac1 & 1.2919 & A [38] \\
H3K18ac1K23ac1 & 1.6818 & A [38] \\
H3K27me1 & 0.5929 & A [52] \\
H3K27me2 & 0.4272 & S [52] \\
H3K27me3 & 0.2679 & S [52] \\
H3K36me1 & 0.8803 & A [52] \\
H3K36me2 & 0.5669 & A [53] \\
H3K56ac1 & 3.8155 & A [38] \\
H3K79me1 & 0.6671 & A [54] \\
H3K79me2 & 0.5661 & A [54] \\
H4K5/K8/K12/K16ac1 & 1.1968 & A [38] \\
H4K5/K8/K12/K16ac2 & 1.5118 & A [38] \\
H4K5/K8/K12/K16ac3 & 1.6048 & A [38] \\
H4K5K8K12K16ac4 & 1.5483 & A [38] \\
H4K20me1 & 0.5884 & A [52] \\
H4K20me2 & 0.2283 & S [55] \\
H4K20me3 & 0.1459 & S [56] \\
\hline
\end{tabular}

${ }^{1} \mathrm{me}=$ Methyl

${ }^{2} \mathrm{ac}=$ Acetyl

${ }^{3}$ Relative turnover, with respect to the relevant unmodified peptide, is determined for various modified forms of $\mathrm{H} 3$ and $\mathrm{H} 4$.

${ }^{4} \mathrm{~A}=$ active marks

${ }^{5} \mathrm{~S}=$ silent marks

chaperones responsible for histone eviction and replacement. To a lesser extent, our turnover measurements may also reflect how quickly the histones become modified into a different peptide; for instance, an unmodified peptide that becomes quickly acetylated would probably have a faster turnover than another peptide that is less rapidly modified.

When mechanistically considering histone turnover in the context of transcription, another non-mutually exclusive pathway for histone turnover emerges. Several models have proposed the displacement of the nucleosome encountered by RNA polymerase onto the upstream DNA strand [36] or even onto the nascent RNA strand, followed by rebinding onto DNA [37].We believe that our measurements reflect this nucleosomal event only to a small extent, as we tracked the incorporation of newly synthesized histones. In particular, given the reported high affinity of $\mathrm{H} 2 \mathrm{~A}$ and $\mathrm{H} 2 \mathrm{~B}$ for RNA, it is unlikely that our observed turnover of H2A and $\mathrm{H} 2 \mathrm{~B}$ occurs during the RNA transition state [37]. However, the lack of preferential affinity for either DNA or RNA by the $\mathrm{H} 3 / \mathrm{H} 4$ tetramer as reported in the same 
study may facilitate $\mathrm{H} 3 / \mathrm{H} 4$ turnover during this transition state when the tetramer is no longer bound to the $\mathrm{H} 2 \mathrm{~A} / \mathrm{H} 2 \mathrm{~B}$ dimer.

A major strength of mass spectrometric analysis is the ability to simultaneously sequence and quantify multiple modifications on the same histone peptide. In the 9-17 peptide on histone H3 (KSTGGKAPR), we observed the presence of both methylation and acetylation on $\mathrm{K} 9$ and K14 in HeLa cells. Interestingly, for H3K9me1K14ac1, the turnover is faster than for the exclusively monomethylated $\mathrm{H} 3 \mathrm{~K} 9 \mathrm{me} 1$ peptide, but slower than for the exclusively monoacetylated H3K9/K14ac1 peptide. For $\mathrm{H} 3 \mathrm{~K} 9 \mathrm{me} 2 \mathrm{~K} 14 \mathrm{ac} 1$, the turnover is slower than for both H3K9me2 and H3K9/K14ac1. These two observations suggest that histone acetylation, generally considered an active mark, is epistatic to active methyl marks (such as H3K9me1) yet antagonistic towards silent methyl marks [38]. The presence of both active and silent marks in the H3K27K36 peptide (KSAPATGGVKKPHR), such as H3K27me2K36me1, is also consistent with this trend. In particular, the $\mathrm{H} 3 \mathrm{~K} 27 \mathrm{me} 2 \mathrm{~K} 36 \mathrm{me} 1$ peptide has a much slower turnover than a peptide containing either the silent mark H3K27me 2 or the active mark H3K36me1 (Table 1). Likewise, the H3K27me1K36me2 peptide has a slower turnover than a peptide containing either H3K27me1 or H3K36me2. However, it should be noted that the slower turnover of these doubly modified peptides is not believed to result simply from the total number of methyl groups, because the H3K27me1K36me2 peptide has a faster turnover than the $\mathrm{H} 3 \mathrm{~K} 27 \mathrm{me} 2 \mathrm{~K} 36 \mathrm{me} 1$ peptide.

The presence of antagonistic PTMs may result in a chromatin domain similar to bivalent domains, which contain histones bearing H3K4me3 and H3K27me3 marks, and are believed to poise genes for either activation or silencing [39]. In principle, the conversion of a bivalent domain to either a fully activating or silencing domain can be achieved by histone-modifying enzymes or replacement of the histone molecule with a new unmodified histone that becomes modified. Given that known bivalent domains are bound by polycomb proteins that methylate $\mathrm{H} 3 \mathrm{~K} 27$, the former mechanism explaining how bivalent domains function in vivo seems more likely [40]. Thus, a slower histone turnover would be expected if the bivalent domains switch epigenetic function through modification changes rather than protein eviction and exchange, consistent with our observations for the H3K9me2K14ac and H3K27me2K36me1 peptides. We believe a similar logic can be applied to binary switch domains; for instance, an effector molecule (that is, heterochromatin protein 1) recognizing methylation on $\mathrm{H} 3 \mathrm{~K} 9$ would engage in competitive binding against another effector molecular recognizing a phosphorylation on H3S10 [41].
Another layer of complexity for histone $\mathrm{H} 3$ is that it exists as three major variants: H3.1, H3.2 and H3.3, and the less abundant, centromere-specific variant CENP-A. Generally, H3.2 and H3.3 are associated with silent and active gene expression, respectively, whereas the evolutionarily younger H3.1 variant is associated with both expression states [42]. Because high-performance liquid chromatography (HPLC) fractionation is able to resolve H3.1, H3.2 and H3.3, we can examine the H3 variant specific turnover of peptides with particular modifications [43]. In general, we found that turnover of the modified peptides from the three $\mathrm{H} 3$ variants did not differ significantly from one other (Table 3). In quiescent human lymphocytes that were stimulated to reenter the cell cycle, different histone $\mathrm{H} 3$ variants were observed to exchange with each other $[29,44]$ Because our steady-state measurements were performed on actively dividing and asynchronous HeLa cells, it is likely that this difference would not be observed generally for $\mathrm{H} 3$ variant turnover. A notable exception is K36 dimethylation; the $\mathrm{H} 3.2$ peptide containing this

Table 3 H3 variant-specific turnover.

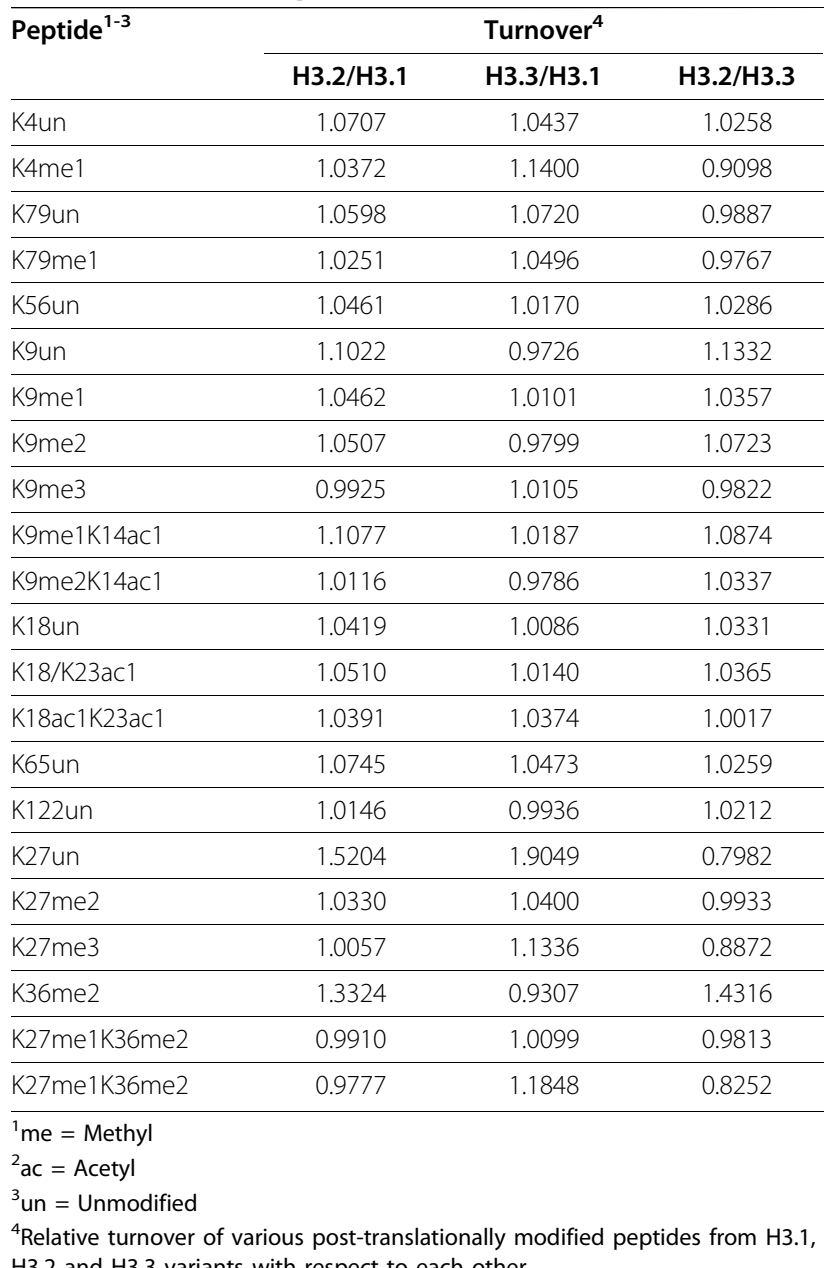


modification has a greater turnover than $\mathrm{H} 3.1$ or H3.3. Previous studies have shown that K36me2 is generally enriched in H3.3 over H3.2 [45]. Based on our turnover data, we speculate that the elevated turnover of K36me2 in H3.2 is essential for maintaining this PTM at a low level, and that it is the absence of K36me2 on H3.2 rather than its presence on $\mathrm{H} 3.3$ that is crucial for epigenetic function. Future experiments to test this hypothesis could resort to substitution of site-directed mutagenesis, with $\mathrm{K} 36$ on H3.2 mutated to a cysteine and then alkylated with the appropriate reagent to mimic dimethylation. Wild-type H3.2 contains a single cysteine at position 110, which can be mutated to an alanine to prevent derivatization [46]. Similarly, a 'K36me1 mimic' can be made on H3.3 to prevent dimethylation [46].

The unmodified 27-40 peptide that contains K27 and K36 also has a higher turnover in both H3.2 and H3.3 than inH3.1. We suspect that this is due to the fact that K27 and K36 become immediately methylated in both H3.2 and H3.3 variants respectively, as both PTMs are known to be enriched on the two variants [45]. Consequently, the unmodified peptide in the H3.2 and H3.3 fractions should turn over faster than in H3.1, because it is immediately methylated into a different peptide.

\section{Conclusion}

Using mass spectrometry and SILAC, we found that histones are generally stable proteins, with the $\mathrm{H} 2 \mathrm{~A}$ variants exhibiting the largest range of global turnover rates, and H1.4 turnover being faster than that of $\mathrm{H} 3$ and H4. Exploring the relationship between post-translational modifications and turnover, we found that turnover is significantly greater when a histone peptide becomes acetylated than when it is methylated. When classifying the $\mathrm{H} 3$ and $\mathrm{H} 4$ modified peptides according to epigenetic function, we found that active marks have a significantly faster turnover than silent marks. However, the dual presence of a silencing and activating mark on the same peptide led to vastly distinct turnover rates compared with either mark alone. The various modified forms of the H3 variants (H3.1, H3.2 and H3.3) generally had a similar global turnover, with the notable exception of K36me2. In conclusion, this study offers novel insights into histone turnover by using techniques complementary to those already in standard use by the general chromatin biology community to examine the role of histone turnover in epigenetic regulation.

\section{Methods}

\section{Cell culture maintenance and SILAC time course}

HeLa S3 were maintained between $5-10 \times 10^{5}$ cells $/ \mathrm{ml}$ throughout the experiment and, before the time course, were grown in minimum essential Joklik modified media
(Sigma Aldrich, St. Louis, MO, USA) as previously described [22]. At the start of the time course, cultures were pelleted at $300 \mathrm{~g}$ for 3 minutes in a refrigerated centrifuge, decanted, and resuspended in Joklik media depleted of unlabeled lysine (ThermoScientific HyClone, Logan, UT, USA) and supplemented with L-lysine${ }^{13} \mathrm{C}_{6}{ }^{15} \mathrm{~N}_{2}$ (Cambridge Isotope Laboratories Inc., Cambridge, MA, USA), $5 \%$ fetal bovine serum (ThermoScientific Hyclone), penicillin, streptomycin and 1\% Glutamax (Invitrogen, Carlsbad, USA). Before resuspension, flasks were rinsed with Joklik media depleted of lysine. Every 24 hours for 6 days, half of the culture was separated by centrifugation at $600 \mathrm{~g}$, washed twice with Tris-buffered saline, flash-frozen in liquid $\mathrm{N}_{2}$, and stored at $-80^{\circ} \mathrm{C}$. The culture was replenished with an approximately equal volume of labeled media after sample collection.

\section{Nuclei isolation and histone extraction}

Cell pellets were thawed on ice before nuclei isolation and histone extractions as previously described [47]. Briefly, cells were lysed using NP-40 in nuclei isolation buffer with $5 \mu \mathrm{mol} / \mathrm{l}$ microcystin, $0.3 \mathrm{mmol} / \mathrm{l} 4$-(2-aminoethyl) benzenesulfonyl fluoride hydrochloride (AEBSF) and $10 \mathrm{mmol} / \mathrm{l}$ sodium butyrate. Histones were isolated from nuclei by extraction with $0.4 \mathrm{~N} \mathrm{H}_{2} \mathrm{SO}_{4}$, precipitated with trichloroacetic acid, washed in acetone, dried overnight and resuspended in water.

\section{Reversed-phase HPLC separation of bulk histone}

Based on the Bradford assay, $125 \mu \mathrm{g}$ of protein was allocated for one-pot propionic anhydride derivatization. The remaining extract was separated on a C18 column (4.6 mm internal diameter $\times 250 \mathrm{~mm}$ (Vydac, Hesperia, CA, USA) using HPLC (System Gold HPLC; Beckman Coulter, Fullerton, CA, USA) with a gradient of $30-60 \%$ B over $100 \mathrm{~min}$, followed by 20 minutes at 100\% B (buffer $A$ was $5 \%$ acetonitrile in $0.2 \%$ trifluoroacetic acid (TFA), buffer B was $90 \%$ acetonitrile in $0.188 \%$ TFA) and a flow rate of $0.8 \mathrm{ml} / \mathrm{min}$. Fractions spanning a single variant were pooled, and then dried to completion in a vacuum centrifuge.

\section{Histone preparation for MS analysis}

The $125 \mu \mathrm{g}$ bulk extract and HPLC-separated histone H3.1, H3.2, H3.3 and H4 were derivatized and desalted for MS as previously described, with the exception that the reagent was composed of 3:1 isopropanol:propionic anhydride instead of 3:1 methanol:propionic anhydride [48]. For HPLC-purified H1, H2A and H2B, samples were resuspended in $100 \mathrm{mmol} / \mathrm{l}$ ammonium bicarbonate ( $\mathrm{pH}$ 6-7), digested using trypsin for 20 minutes with a $20: 1$ substrate/enzyme ratio, and subsequently propionylated. 


\section{MS and MS/MS analysis}

Samples were loaded by an autosampler (AS-2; Eksigent Technologies Inc., CA, USA) onto a $75 \mu \mathrm{m}$ fused silica capillary column with ESI tip hand packed with $130 \mathrm{~mm}$ of $\mathrm{C} 18$ reverse phase resin $(5 \mu \mathrm{m}$ particles, $200 \AA$ pore size) (Magic C18; Michrom BioResources Inc., Auburn, CA, USA). Samples were resolved on a 110 minute 1$100 \%$ buffer $B$ gradient (buffer $A=0.1 \mathrm{~mol} / \mathrm{l}$ acetic acid, Buffer $\mathrm{B}=70 \%$ acetonitrile in $0.1 \mathrm{~mol} / \mathrm{l}$ acetic acid) at a flow rate of $0.070 \mathrm{ml} / \mathrm{min}$ controlled by an HPLC pump (1200 series; Agilent, Santa Rosa, CA, USA). The HPLC was coupled to a mass spectrometer (LTQ-Orbitrap; ThermoFisher Scientific, Carlsbad, CA, USA) with a resolution of 30,000 for full MS followed by seven datadependent MS/MS analyses. Ions selected for MS/MS interrogation were placed on an exclusion list for 30 seconds. Targeted runs were performed on a number of samples to increase the identification of low-abundance modifications.

\section{Data analysis and modeling}

Peptide abundance was calculated by manual chromatographic peak integration of full MS scans using Qual Browser software (version 2.0.7; ThermoFisher Scientific Inc.). Peptide sequence and modifications were confirmed by inspection of the MS/MS data. To identify histone $\mathrm{H} 1, \mathrm{H} 2 \mathrm{~A}$ and $\mathrm{H} 2 \mathrm{~B}$ peptides, a database search was performed using the SEQUEST algorithm within the Bioworks Browser (version 3.3; ThermoFisher Scientific). The search was performed against human histone variants for fully enzymatic tryptic digests, allowing for five missed cleavage sites due to the propionyl derivatization, propionylation of unmodified and monomethylated lysines and $\mathrm{N}$-termini $(+56.026 \mathrm{Da})$ and oxidation of methionine (+15.995 Da).

As a labeling convention, we appended each peptide with two numbers, the first referring to the total number of lysines and the second to the number of labeled lysines. For instance, H3K9me1 2:0, H3K9me1 2:1 and H3K9me1 2:2 refer to the same 9-17 monomethylated peptide containing 0 , one and two isotopically labeled lysines, respectively. For quantifying the dynamics of histone turnover, we normalized the relative abundances of each labeled state with respect to all labeled states of the same modified peptide to determine the relative distribution of that labeled state. Thus, we normalized H3K9me1 2:0 to the sum of the H3K9me1 2:0, 2:1 and 2:2 peptides. This method of normalization avoids complications arising from variations in ionization efficiencies between peptides with different modification states.

A fundamental requirement of our turnover modeling is that the relative abundance of a post-translationally modified peptide, summed across all its isotopically labeled states, should remain at a steady state. Assuming that $95 \%$ (standard score $=1.96$ ) of our observed data can be accounted by a measurement variability of $10 \%$, a commonly cited upper bound, we checked whether the standard deviation of the relative abundances for a particular modified peptide across the time course remained within $0.10 / 1.96=0.051$. For instance, if H3K79un, H3K79me1 and H3K79me2 fitted this criterion, we declared that all the modified forms of the peptide were at steady state relative to each other. For peptides that we never observed to be modified, such as the H4 24-35 peptide, we could not make this calculation because we normalized the peptide to itself and we assumed that these unmodified peptides were at steady state.

For each modified peptide, we then fitted a set of differential equations (see Additional file 1 and 3) to the relative abundance distributions for all labeled states using MATLAB (version 7.9.0; Mathworks, Natick, MA, USA) and iterated the program using 100-200 different initial parameter values to determine the set of optimized parameter values that results in the lowest objective or error value. For statistical comparison, we used either the Wilcoxon rank sum test or Kruskal-Wallis test (MATLAB version 7.9.0) for data points that were normally or non-normally distributed, respectively.

We adopted two independent and complementary approaches to assess the quality of the parameter estimates and the fit of the model to the data. Specifically, we examined the squared norm of the residual and computed confidence regions in parameter subspaces to elucidate parameter significance and independence.

In parameter estimation problems, confidence intervals (based on the Student $t$-test distribution) and/or elliptical confidence regions (based upon a Taylor series expansion around the parameter estimate) are often used to provide a range of values over which the parameter estimates are valid (that is, how much the estimated parameters are allowed to vary while still allowing the model to fit the data well). However, these aforementioned approaches, which are based on linear approximations [49], are only valid when the parameters vary symmetrically around the optimal estimates, and are not accurate for models with even moderate degrees of non-linearity [50]. To avoid the limitations associated with the inherent assumptions of these methods, we computed confidence regions around the parameter estimates using the $F$-test method (see Additional file 8) [51]. This $F$-test approach was applied to every pair of parameters to manually validate that the parameter estimates were indeed significant from zero and to visually assess any degree of nonlinearity in the confidence regions. The parameter estimates were found to be significant, and it was also observed that the confidence region was only slightly nonlinear (see Additional file 8). 


\section{Additional material}

Additional file 1: Figure S1: Tandem mass spectrometry (MS/MS) spectra of labeled peptides analyzed. MS/MS spectra of partially and fully ${ }^{13} \mathrm{C}_{6}{ }^{15} \mathrm{~N}_{2}$-lysine labeled peptides, where the red and blue peaks correspond to the $\mathrm{b}$ and $\mathrm{y}$ ions annotated by Bioworks Browser.

Additional file 2: Table S1: List of all histone peptides analyzed: All histone peptides quantified in our experiment are provided below, with their charge state, expected and observed mass to charge ratio $(\mathrm{m} / \mathrm{z})$. ac $=$ Acetyl, $\mathrm{me}=$ methyl, ox = oxidation $\mathrm{pr}=$ propionyl, $\mathrm{un}=$ unmodified . *Charge state of the peptide is included; tunable to differentiate based on MS/MS

Additional file 3: Figure S2: Detection of labeled isotopes. Mass spectrometry spectrum of the unmodified H3 $18-26$ peptide after 1 day of ${ }^{13} \mathrm{C}_{6}{ }^{15} \mathrm{~N}_{2}$-lysine labeling, where the isotopic distributions for the peptide containing two ${ }^{12} \mathrm{C}_{6}{ }^{14} \mathrm{~N}_{2}$-lysines, one ${ }^{12} \mathrm{C}_{6}{ }^{14} \mathrm{~N}_{2}$-lysine and one ${ }^{13} \mathrm{C}_{6}^{15} \mathrm{~N}_{2}$-lysine, and two ${ }^{13} \mathrm{C}_{6}^{15} \mathrm{~N}_{2}$-lysines are detected.

Additional file 4: Figure S3: Model for histone turnover. Set of differential equations that extrapolate histone turnover for a peptide containing one, two, three and four lysines. We found that at steady state, the rate of histone removal for a particular labeled state should equal the sum of all the rates of histone addition. This provides a constraint in the optimization procedure. Furthermore, because the rate of addition $=$ rate of removal, $k_{1}$ becomes a measure of overall turnover for that peptide. For a peptide containing two lysines, we needed to include an additional factor of 2 for $k_{1}$ because we were unable to differentiate which of the two lysines are isotopically labeled. For similar reasons, we modifid the differential equations for peptides containing more than one lysine. $P_{\#}=$ relative abundance of peptide, where \# indicates the number of labeled lysines. $k_{-1}=$ Rate of histone removal. $k_{\#}$ = Rate of histone addition, where \# indicates the number of labeled lysines.

Additional file 5: Figure S4: Steady state assumption. Steady state levels for histone post-translational modifications. Standard deviations (vertical bars) of the relative abundances for the $\mathrm{H} 3$ and $\mathrm{H} 4$ peptides across the labeling time course are shown relative to their respective means (black circles). Horizontal dashed lines denote a standard deviation of 0.051 , the threshold at which $95 \%$ of the observed variability cannot be accounted by 5-10\% of the instrument measurement variability. ac $=$ Acetyl, $\mathrm{me}=$ methyl, un $=$ unmodified.

\section{Additional file 6: Figure S5: Comparison of turnover between}

histones. (A) Relative distribution of the fully labeled H2A variant (black diamond), H3 (green diamond), $\mathrm{H} 2 \mathrm{~b}$ variant (pink diamond), $\mathrm{H} 4$ (dark blue diamond) and $\mathrm{H} 1.4$ (light blue diamond) core peptides during the time course. Lines represent fits based on the optimized kinetic parameters for the respective peptides. (B) Contour plots of the kinetic parameters for the respective core peptides (same color scheme as in (A)), where $k_{\max }=k_{1}$ for $H 2 A, H 2 B, H 3$ and $H 4$, and $k_{2}$ for $H 1$.4. The limits of the contour plots are defined by $z(k) \times\left(1+2 / 5 \times F_{0.05}(2,5)\right)$ for all the histone peptides except the $\mathrm{H} 1.4$ peptide, where the limit is defined by $z$ $(\mathrm{k}) \times\left(1+3 / 11 \times F_{0.05}(3,11)\right)$ because of the additional lysine on the $\mathrm{H} 1.4$ peptide.

Additional file 7: Figure S6: Progressive modifications and turnover. Turnover modeling (colored lines) of the relative distribution of the fully labeled unmodified (H3K18un, blue circle), monoacetylated (H3K18/ $\mathrm{K} 23 \mathrm{ac} 1$, green circle) and diacetylated (H3K18ac1 K23ac1, red circle) H3 18-26 peptides across the labeling time course. Note the increasingly faster accumulation of the fully labeled peptides (increasingly leftward shift) as acetylation increases.

Additional file 8: Figure S7: Confidence regions for parameter estimates. For each pair of estimated rate constants, we compared confidence regions using the F-test, which is presented below, where $k$ is the vector containing the rate constants (that is, $k_{0}, k_{1}, \ldots, k_{N}$ ), $\hat{k}$ is the vector of estimates for these rate constants as determined by solving the regression problem, $z(k)$ is the value of the objective function for the regression problem (that is, the sum of the squared differences between the predicted and actual relative abundances), and $F_{p, n-p}^{a}$ is the upper $\alpha$ critical value for the $F$ distribution for $p$ parameters and $n$ data points.
Thus, the corresponding confidence region for a given estimate $\hat{k}$ is the union of all $k$ values that satisfy equation 1 .

\section{Acknowledgements}

We thank all members of the Garcia laboratory for helpful discussions and experimental assistance, and Bo Xu and Ned Wingreen for helpful discussion on the modeling. BAG is supported by an NSF Early Faculty CAREER award, NSF grant (CBET-0941143), Princeton University and a grant supported by award number DP2OD007447 from the Office Of The Director, National Institutes of Health. BMZ is supported by the NSF GRFP. PAD also gratefully acknowledges funding from an NIH F32 NRSA postdoctoral fellowship. RSL acknowledges support from a Sigma Xi research grant.

\section{Author details}

'Department of Molecular Biology, Princeton University, Princeton NJ, 08544, USA. ${ }^{2}$ Department of Chemistry, Princeton University, Princeton NJ, 08544 , USA

\section{Authors' contributions}

RSL conducted the labeling time course, prepared the histone samples and helped analyze the MS data. BMZ helped prepare the histone samples, analyzed the MS data, developed the turnover model and wrote the manuscript. PAD helped develop the turnover model and provided the quantitative estimates for the parameters and confidence regions. BAG conceived and designed the study. All authors read and approved the final manuscript.

\section{Competing interests}

The authors declare that they have no competing interests.

Received: 27 September 2010 Accepted: 6 December 2010 Published: 6 December 2010

\section{References}

1. Margueron R, Reinberg D: Chromatin structure and the inheritance of epigenetic information. Nature Reviews Genetics 2010, 11:285-296.

2. Wysocka J, Swigut T, Xiao H, Milne TA, Kwon SY, Landry J, Kauer M, Tackett AJ, Chait BT, Badenhorst P, Wu C, Allis CD: A PHD finger of NURF couples histone $\mathrm{H} 3$ lysine4 trimethylation with chromatin remodeling. Nature 2006, 442:86-90.

3. Ahmad K, Henikoff S: The histone variant H3.3 marks active chromatin by replication-independent nucleosome assembly. Mol Cell 2002, 9:1191-1200

4. Hayashi T, Fujita Y, Iwasaki O, Adachi Y, Takahashi K, Yanagida M: Mis16 and Mis 18 are required for CENP-A loading and histone deacetylation at centromeres. Cell 2004, 118:715-729.

5. Boeger H, Griesenbeck J, Strattan JS, Kornberg RD: Nucleosomes unfold completely at a transcriptionally active promoter. Mol Cell 2003, 11:1587-1598.

6. Chalkey G, Maurer HR: Turnover of template-bound histone. Biochemistry 1965, 54:498-505.

7. Bondy S: The synthesis and decay of histone fractions and of deoxyribonucleic acid in the developing avian brain. Biochem J 1971, 123:465-469.

8. Hereford L, Osley MA, Ludwig II TR, McLaughlin CS: Cell-cycle regulation of yeast histone mRNA. Cell 1981, 24:367-375.

9. Tagami H, Ray-Gallet D, Almouzni G, Nakatani Y: Histone H3.1 and H3.3 complexes mediate nucleosome assembly pathways dependent or independent of DNA synthesis. Cell 2004, 116:51-61.

10. Osley MA: The regulation of histone synthesis in the cell cycle. Annu Rev Biochem 1991, 60:827-861.

11. Ruhl D, Jin J, Cai Y, Swanson S, Florens L, Washburn MP, Conaway RC, Conaway JW, Chrivia JC: Purification of a human SRCAP complex that remodels chromatin by incorporating the histone variant H2A.Z into nucleosome. Biochemistry 206, 45:5671-5677.

12. Meeks-Wagner D, Hartwell LH: Normal stoichiometry of histone dimer sets is necessary for high fidelity of mitotic chromosome transmission. Cell 1986, 44:43-52. 
13. Morillo-Huesca M, Maya D, Munoz-Centeno MC, Singh RK, Oreal V, Reddy GU, Liang D, Geli V, Gunjan A, Chavez S: FACT prevents the accumulation of free histones evicted from transcribed chromatin and a subsequent cell cycle delay in G1. PloS Genetics 2010, 6.

14. Louie AJ, Dixon GH: Synthesis, acetylation, and phosphorylation of histone IV and its binding to DNA during spermatogenesis in trout. Proc Natl Acad Sci USA 1972, 69:1975-1979.

15. Misteli T, Gunjan A, Hock R, Bustin M, Brown DT: Dynamic binding of histone $\mathrm{H} 1$ to chromatin in living cells. Nature 2000, 408:877-881.

16. Dion M, Kaplan T, Kim M, Buratowski S, Friedman N, Rando OJ: Dynamics of replication-independent histone turnover in budding yeast. Science 2007, 315:1405-1408

17. Mito Y, Henikoff JG, Henikoff S: Histone replacement marks the boundaries of cis-regulatory domains. Science 2007, 315:1408-1411.

18. Deal R, Henikoff JG, Henikoff S: Genome-wide kinetics of nucleosome turnover determined by metabolic labeling of histones. Science 2010, 328:1161-1164

19. Garcia BA: Mass spectrometric analysis of histone variants and posttranslational modifications. Front Biosci (Schol Ed) 2009, 1:142-153.

20. Yuan J, Rabinowitz JD: Differentiating metabolites formed from de novo synthesis versus macromolecule decomposition. J Am Chem Soc 2007, 129:9294-9295.

21. Tabb D, Vega-Montoto L, Rudnick PA, Variyath AM, Ham AJ, Bunk DM, Kilpatrick LE, Billheimer DD, Blackman RK, Cardasis HL, Carr SA, Clauser KR, Jaffe JD, Kowalski KA, Neubert TA, Regnier FE, Schilling B, Tegeler TJ, Wang M, Wang P, Whiteaker JR, ZImmerman LJ, Fisher SJ, Gibson BW, Kinsinger CR, Mesri M, Rodriguez H, Stein SE, Tempst P, Paulovich AG, Liebler DC, Spiegelman C: Repeatability and reproducibility in proteomic identifications by liquid chromatography-tandem mass spectrometry. $J$ Proteome Res 2010, 9:761-776.

22. Zee BM, Levin RS, Xu B, Leroy G, Wingreen NS, Garcia BA: In vivo residuespecific histone methylation dynamics. J Biol Chem 2009.

23. Trojer $\mathrm{P}$, Zhang J, Yonezawa $M$, Schmidt $A$, Zheng $H$, Jenuwein $T$, Reinberg $D$ : Dynamic histone $\mathrm{H} 1$ isotope 4 methylation and demethylation by histone lysine methyltransferase G9a/KMT1C and the Jumonji domain-containing JMJD2/KDM4 proteins. J Biol Chem 2009, 284:8395-8405.

24. Clausell J, Happel N, Hale TK, Doenecke D, Beato M: Histone H1 subtypes differentially modulation chromatin condensation without preventing ADP-dependent remodeling by SWI/SNF or NURF. PLoS One 2009, 4 e0007243.

25. Creyghton MP, Markoulake S, Levine SS, Hanna J, Lodato MA, Sha K, Young RA, Jaenisch R, Boyer LA: H2AZ is enriched at polycomb complex target genes in ES cells and is necessary for lineage commitment. Cell 2008, 135:649-661.

26. Li B, Pattenden SG, Lee D, Gutiérrez J, Chen J, Seidel C, Gerton J, Workman JL: Preferential occupancy of histone variant $\mathrm{H} 2 \mathrm{AZ}$ at inactive promoters influences local histone modifications and chromatin remodeling. Proc Natl Acad Sci USA 2005, 102:18385-18390.

27. Worcel A, Han S, Wong ML: Assembly of newly replicated chromatin. Cell 1978, 15:969-977.

28. Grove GW, Zweidler A: Regulation of nucleosomal core histone variant levels in differentiating murine erythroleukemia cells. Biochemistry 1984, 23:4436-4443.

29. Wu RS, Panusz HT, Hatch CL, Bonner WM: Histones and their modifications. CRC Crit Rev Biochem 1986, 20:201-263.

30. Commerford SL, Carsten AL, Cronkite EP: Histone turnover within nonproliferating cells. Proc Natl Acad Sci USA 1982, 79:1163-1165.

31. Luger K, Mäder AW, Richmond RK, Sargent DF, Richmond TJ: Crystal structure of the nucleosome core particle at $2.8 \AA$ resolution. Nature 1997, 389:251-260.

32. Matsumoto $H$, Hawke $D$, Kobayashi $R$, Verreault A: A role for cell-cycle regulated histoen $\mathrm{H} 3$ lysine 56 acetylation in the DNA damage response. Nature 2005, 436:294-298.

33. Wunsch $A$, Jackson $V$ : Histone release during transcription: acetylation stabilizes the interaction of the $\mathrm{H} 2 \mathrm{~A}-\mathrm{H} 2 \mathrm{~B}$ dimer with the $\mathrm{H} 3-\mathrm{H} 4$ tetramer in nucleosomes that are on highly positively coiled DNA. Biochemistry 2005, 44:16351-16364.

34. Narlikar GJ, Fan H, Kingston RE: Cooperation between complexes that regulation chromatin structure and transcription. Cell 2002, 108:475-487.

35. Clapier CR, Cairns BR: The biology of chromatin remodeling complexes. Annu Rev Biochem 2009, 78:273-304.
36. Clark DJ, Felsenfeld G: A nucleosome core is transferred out of the path of a transcribing polymerase. Cell 1992, 71:11-22.

37. Levchenko $V$, Jackson $V$ : Histone release during transcription: NAP1 forms a complex with $\mathrm{H} 2 \mathrm{~A}$ and $\mathrm{H} 2 \mathrm{~B}$ and facilitates a topologically dependent release of $\mathrm{H} 3$ and $\mathrm{H} 4$ from the nucleosome. Biochemistry 2004, 43:2359-2372.

38. Wang Z, Zang C, Cui K, Schones DE, Barski A, Peng W, Zhao K: Genomewide mappings of HATs and HDACs reveals distinct functions in active and inactive genes. Cell 2009, 138:1019-1031.

39. Bernstein BE, Mikkelsen TS, Xie X, Kamal M, Huebert DJ, Cuff J, Fry B, Meissner A, Wernig M, Plath K, Jaenisch R, Wagschal A, Feil R, Schreiber SL, Lander ES: A bivalent chromatin structure marks key developmental genes in embryonic stem cells. Cell 2006, 125:315-326.

40. Ku M, Koche RP, Rheinbay E, Mendenhall EM, Endo M, Mikkelsen TS, Presser A, Nusbaum C, Xie X, Chi AS, Adli M, Kasif S, Ptaszek LM, Cowan CA, Lander ES, Koseki H, Bernstein BE: Genomewide analysis of PRC1 and PRC2 occupancy identifies two classes of bivalent domains. PloS Genetics 2008, 4:e1000242.

41. Fischle $W$, Wang $Y$, Allis CD: Binary switches and modification cassettes in histone biology and beyond. Nature 2003, 425:475-479.

42. Hake $\mathrm{SB}$, Allis CD: Histone $\mathrm{H} 3$ variants and their potential role in indexing mammalian genomes: the "H3 barcode hypothesis". Proc Natl Acad Sci USA 2006, 103:6428-6435.

43. Hake SB, Garcia BA, Kauer M, Baker SP, Shabanowitz J, Hunt DF, Allis CD: Serine 31 phosphorylation of histone variant $\mathrm{H} 3.3$ is specific to regions bordering centromeres in metaphase chromosomes. Proc Natl Acad Sci USA 2005, 102:6344-6349.

44. Wu RS, Tsai S, Bonner WM: Changes in histone H3 composition and synthesis pattern during lymphocyte activation. Biochemistry 1983, 22:3868-3873

45. Hake SB, Garcia BA, Duncan EM, Kauer M, Dellaire G, Shabanowitz J, BazettJones DP, Allis CD, Hunt DF: Expression patterns and post-translational modifications associated with mammalian histone $\mathrm{H} 3$ variants. J Biol Chem 2006, 281:559-568

46. Simon MD, Chu F, Racki LR, de la Cruz CC, Burlingame AL, Panning B, Narlikar GJ, Shokat KM: The site-specific installation of methyl-lysine analogs into recombinant histones. Cell 2007, 128:1003-1012.

47. Garcia BA, Pesavento JJ, Mizzen CA, Kelleher NL: Pervasive combinatorial modification of histone $\mathrm{H} 3$ in human cells. Nat Methods 2007, 4:487-489

48. Plazas-Mayorca MD, Zee BM, Young NL, Fingerman IM, LeRoy G, Briggs SD, Garcia BA: One-pot shotgun quantitative mass spectrometry characterization of histones. J Proteome Res 2009, 8:5367-5374.

49. Asprey SP, Naka Y: Mathematical problems in fitting kinetic models-some new perspectives. J Chem Eng Jpn 1999, 32:328-337.

50. Rooney WC, Biegler LT: Design for model parameter uncertainty using nonlinear confidence regions. AlChE Journal 2004, 47:1794-1804.

51. Seber G, Wild C: Nonlinear regression New York: Wiley; 1989.

52. Barski A, Cuddapah S, Cui K, Roh TY, Schones DE, Wang Z, Wei G, Chepelev I, Zhao K: High-resolution profiling of histone methylations in the human genome. Cell 2007, 129:823-837.

53. Rao B, Shibata Y, Strahl BD, Lieb JD: Dimethylation of histone $\mathrm{H} 3$ at lysine 36 demarcates regulatory and nonregulatory chromatin genome-wide. Mol Cell Biol 2005, 25:9447-9459.

54. Steger DJ, Lefterova MI, Ying L, Stonestrom AJ, Schupp M, Zhuo D, Vakoc AL, Kim JE, Chen J, Lazar MA, Blobel GA, Vakoc CR: Dot1L/KMT4 recruitment and K79 methylation are ubiquitously coupled with gene transcription in mammalian cells. Mol Cell Biol 2008, 28:2825-2839.

55. Trojer P, Li G, Sims RJ, Vaquero A, Kalakonda N, Boccuni P, Lee D, Erdjument-Bromage $H$, Tempst $P$, Nimer SD, Wang YH, Reinberg D: L3MBTL1, a histone-methylation-dependent chromatin lock. Cell 2007, 129:915-928.

56. Schotta G, Lachner M, Sarma K, Ebert A, Sengupta R, Reuter G, Reinberg D, Jenuwein $\mathrm{T}$ : A silencing pathway to induce H3-K9 and H4-K20 trimethylation at constitutive heterochromatin. Genes Dev 2004, 18:1251-1262.

doi:10.1186/1756-8935-3-22

Cite this article as: Zee et al:: Global turnover of histone posttranslational modifications and variants in human cells. Epigenetics \& Chromatin 2010 3:22. 